\title{
Glycogen storage disease due to acid maltase deficiency, infantile onset
}

INSERM

\section{Source}

INSERM. (1999). Orphanet: an online rare disease and orphan drug data base. Glycogen storage disease due to acid maltase deficiency, infantile onset. ORPHA:308552

Glycogen storage disease due to acid maltase deficiency, infantile onset is the most severe form of glycogen storage disease due to acid maltase deficiency, characterized by cardiomegaly with respiratory distress, muscle weakness and feeding difficulties. It is often fatal. 